\title{
Polymer Nanocomposite Processing, Characterization, and Applications 2013
}

\author{
Gaurav Mago, ${ }^{1}$ Suprakas Sinha Ray, ${ }^{2}$ Meisha L. Shofner, ${ }^{3}$ Shanfeng Wang, ${ }^{4}$ and Jin Zhang ${ }^{5}$ \\ ${ }^{1}$ Lubrizol Advanced Materials, Inc., Avon Lake, OH 44012, USA \\ ${ }^{2}$ DST/CSIR Nanotechnology Innovation Centre, National Centre for Nano-Structured Materials, Pretoria 0001, South Africa \\ ${ }^{3}$ School of Materials Science and Engineering, Georgia Institute of Technology, Atlanta, GA 30332, USA \\ ${ }^{4}$ Department of Materials Science and Engineering, The University of Tennessee, Knoxville, TN 37996, USA \\ ${ }^{5}$ Department of Chemical and Biochemical Engineering, University of Western Ontario, London, ON, Canada N6A 5B9
}

Correspondence should be addressed to Gaurav Mago; gauravmago2001@gmail.com

Received 23 December 2013; Accepted 23 December 2013; Published 26 February 2014

Copyright (C) 2014 Gaurav Mago et al. This is an open access article distributed under the Creative Commons Attribution License, which permits unrestricted use, distribution, and reproduction in any medium, provided the original work is properly cited.

Nanoparticles, such as carbon nanotubes, nanoclays, and graphenes, are widely used in the polymer nanocomposites to alter the chemical, mechanical, electrical, optical, and thermal properties. However, a number of critical issues need to be addressed before the full potential of polymer nanocomposites can actually be realized. The improvements in mechanical, thermal, electrical, and rheological properties of polymers by addition of nanoparticles depend upon a number of factors, such as processing technique, interfacial interaction between nanoparticles and host polymers, and state of nanoparticle dispersion. While a number of advances have recently been made in the area of polymer nanocomposites, the studies on understanding of the effects of processing parameters on the structure, morphology, and functional properties of polymer nanocomposites are deficient. The relationships between the structural distributions and the ultimate properties of the polymer nanocomposites also need to be elucidated. There is a need for better characterization techniques to quantify the concentrations and distributions of nanoparticles as well as to assess the nature of the interface between the polymer and nanoparticles. Also, there is a critical need for the development of better models with the ability to predict the mechanical properties of the polymer nanocomposites as functions of relevant factors including nanoparticle orientation, the type of functional groups, and the molecular weight of polymer chain.
Considering the challenges in the area of development of adequate methods of processing for nanocomposites, this special issue was devoted to the emerging polymer nanocomposite processing techniques. Also, this special issue intended to cover the entire range of basic and applied materials research focusing on rheological characterization, nanoparticle dispersion, and functional properties of polymer nanocomposites for sensors, actuators, and other multifunctional applications. This special issue with a total of six papers covers a wide range of areas related to fabrication of triple-component drug-loaded nanocomposites using a modified coaxial electrospinning: three-phase carbon fiber amine functionalized carbon nanotubes epoxy composite: processing, characterization, and multiscale modeling; use of ultrasonication technique for dispersing nanoclay in wood adhesives; effect of chitosan alkali pretreatment on the preparation of electrospun poly( $\varepsilon$-caprolactone)/chitosan blend nanofibrous scaffolds for tissue engineering application; polyethylene/clay nanocomposites produced by in situ polymerization with zirconocene/methylaluminoxane catalyst; and, finally, mechanical properties of natural rubber nanocomposites filled with thermally treated attapulgite.

It is hoped that this special issue will help readers with a wide range of backgrounds to understand the impact of various processing methods as well as nanoparticles on the polymer nanocomposite properties and their multifunctional applications. 


\section{Acknowledgments}

The editors would like to acknowledge the invited and contributing authors and reviewers.

Gaurav Mago Suprakas Sinha Ray Meisha L. Shofner Shanfeng Wang Jin Zhang 

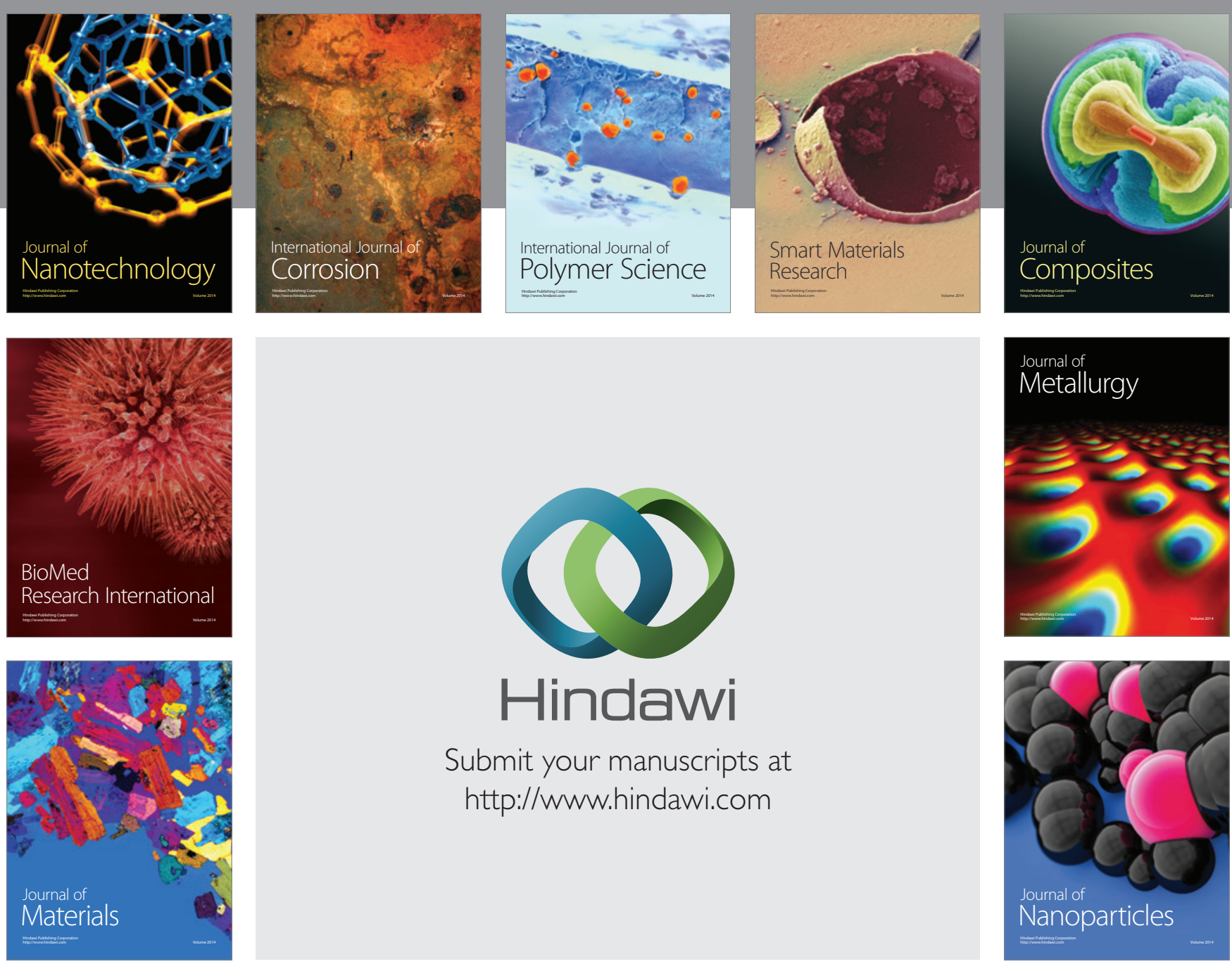

Submit your manuscripts at http://www.hindawi.com
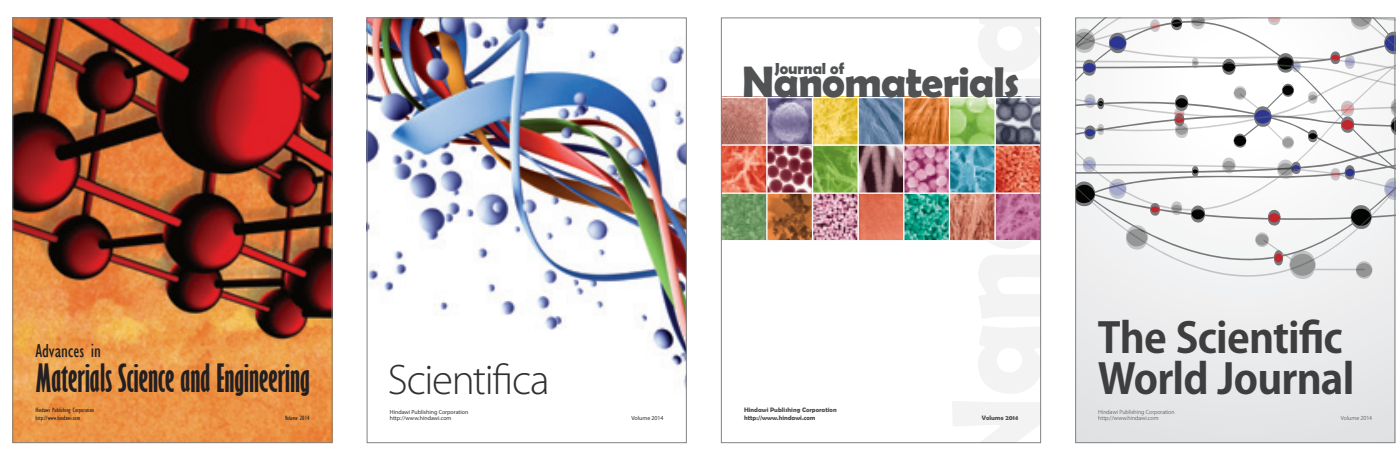

\section{The Scientific World Journal}
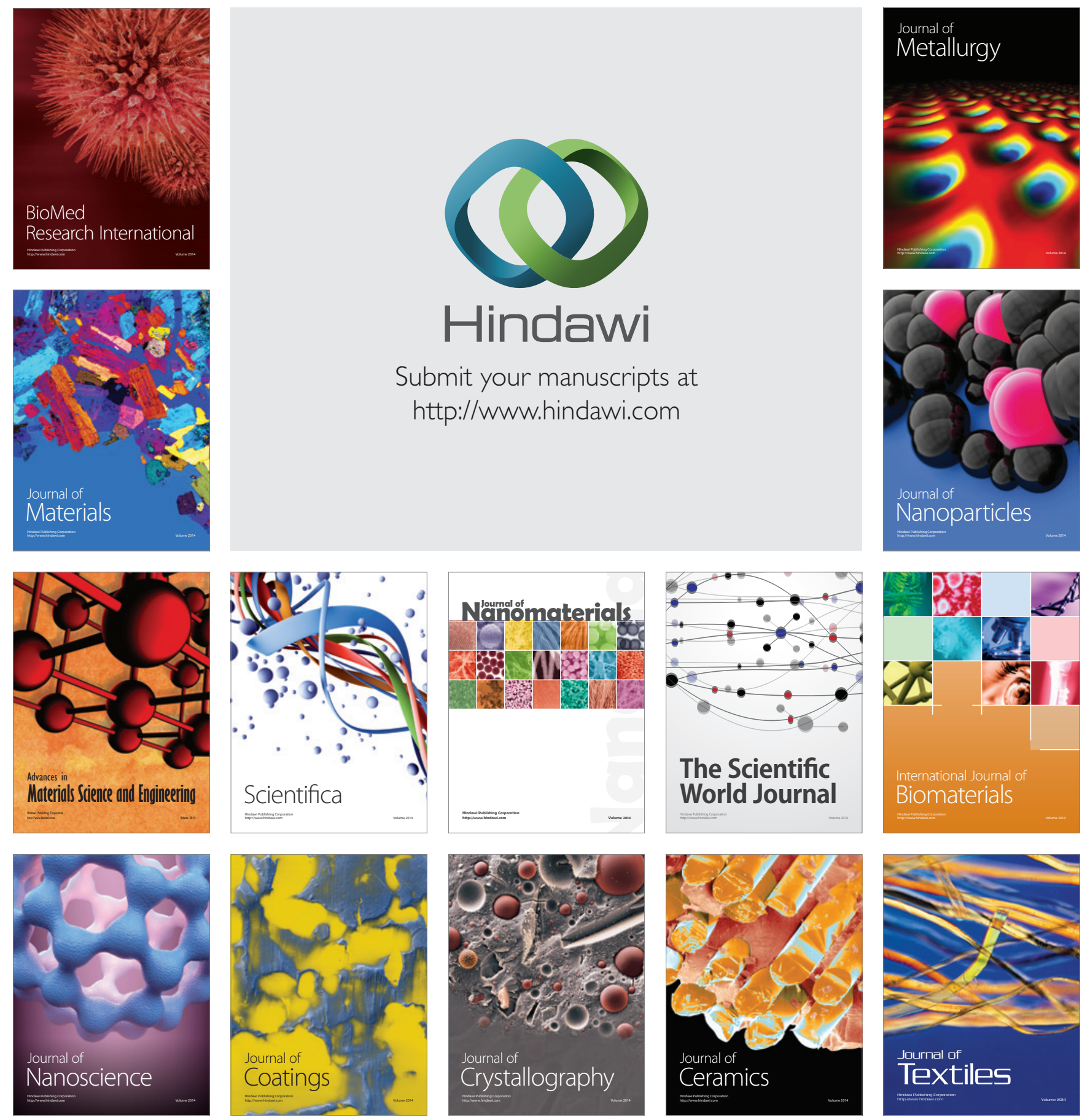